BIBLIOTIKA : Jurnal Kajian Perpustakaan dan Informasi

Volume 3 Nomor 1, 2019

Journal homepage : http://journal2.um.ac.id/index.php/bibliotika

\title{
INSTITUSIONAL REPOSITORY PERPUSTAKAAN PERGURUAN TINGGI (STUDI KASUS PADA PERPUSTAKAAN UNIVERSITAS NEGERI MALANG)
}

\author{
Setiawan ${ }^{*}$, Ali Mas'ud \\ Universitas Negeri Malang
}

\begin{tabular}{|c|c|}
\hline $\begin{array}{l}\text { A R T I C L E } \\
\text { I N F O }\end{array}$ & A B S T R A C T \\
\hline $\begin{array}{l}\text { Article history: } \\
\text { Received: May } 2019 \\
\text { Accepted: } 23 \text { May } 2019 \\
\text { Published: } 31 \text { May } 2019 \\
\text { Keyword: } \\
\text { digital library, institusional } \\
\text { repository }\end{array}$ & $\begin{array}{l}\text { Tujuan dari penelitian ini Untuk mengetahui persoalan-persoalan } \\
\text { perpustakaan Universitas Negeri Malang dalam membangun } \\
\text { institutional repository dan untuk mengetahui tahapan-tahapan pihak } \\
\text { perpustakan Universitas Negeri Malang dalam mengembangkan } \\
\text { dan membangun institutional repository. Metode penelitian yang } \\
\text { digunakan adalah metode penelitian deskriptif analitis. yaitu } \\
\text { ingin mengemukakan beberapa kemungkinan untuk } \\
\text { memecahkan masalah yang aktual dengan jalan } \\
\text { mengumpulkan data, menyusun, atau mengklasifikasikannya, } \\
\text { menganalisa dan menginterprtesikannya Hasil penelitian } \\
\text { persoalan dalam membangun institusional repository di } \\
\text { Universitas Negeri Malang itu antara lain : 1. Masalah hak cipta, } \\
\text { yang diselesaikan dengan cara dilakukan perjanjian tertulis, } 2 \text {. } \\
\text { Sumber Daya Manusia dengan memilih, menentukan } \\
\text { standard tenaga yang betul-betul memiliki kemampuan } \\
\text { dalam Teknologi Informasi,. 3. Plagiarisme dengan } \\
\text { melakukan beberapa tindakan termasuk peraturan-peraturan } \\
\text { dalam men-copy. Hal yang dilakukan perpustakaan UM, } \\
\text { 1.Analisa kebutuhan pengguna, 2. Membuat POB (Prosedur } \\
\text { operasional Baku), 3. Meningkatkan kualitas Sumber Daya } \\
\text { Manusia, 4. Melakukan perbaikan, penggantian terhadap } \\
\text { Sarana dan prasarana ( Hardware, Software, ). Hasil penelitian } \\
\text { ini dijadikan rujukan bagi perguruan tinggi yang ingin } \\
\text { membangun institusional repository, dalam hal memahami } \\
\text { persoalan-persoalan yang dihadapi dan bagaimana tahapan- } \\
\text { tahapan dalam membangun institusional repository tersebut. }\end{array}$ \\
\hline & $\begin{array}{l}\text { The purpose of this study is to find out about library } \\
\text { problems in State University of Malang in building }\end{array}$ \\
\hline
\end{tabular}

\footnotetext{
* Corresponding author.

E-mail addresses: setiawan@um.ac.id (Setiawan)
}

ISSN : 2579-3802 (Online) - BIBLIOTIKA : Jurnal Kajian Perpustakaan dan Informasi is licensed under Creative Commons Attribution-ShareAlike 4.0 International License (http://creativecommons.org/licenses/BY/4.0/). 


\begin{abstract}
institutional repositories and to find out the stages of the State University of Malang library in developing and building institutional repositories. The research method used is descriptive analytical research method. that is to say some possibilities to solve the actual problem by collecting data, compiling, or classifying it, analyzing and interpreting it. The results of the problem research in building institutional repositories at the State University of Malang include: 1. Copyright issues, which are solved by means of written agreements, 2.Human Resources by choosing, determining labor standards who really has the ability in Information Technology. 3. Plagiarism by carrying out several actions including the rules for copying. Things that UM library does, 1. Analyze user needs, 2. Make POB (Standard Operating Procedure), 3. Improve the quality of Human Resources, 4. Make repairs, replace facilities and infrastructure (Hardware, Software,). The results of this study are used as a reference for universities that want to build institutional repositories, in terms of understanding the problems faced and how the stages in building the institutional repository.
\end{abstract}

Perkembangan dan kemajuan Teknologi Informasi banyak dirasakan memiliki manfaat yang sangat besar terhadap kemajuan di bidang ilmu pengetahuan. Dengan kemajuan Teknologi Informasi ini masyarakat harus mampu menyikapi dengan baik dan inovatif, karena tanpa disikapi dengan pengembangan ilmu terutama tentang teknologi informasi pada diri seseorang maka akibatnya masyarakat akan terlindas oleh perkembangan jaman yang dari ke hari semakin berkembang sangat pesat. Menurut Trisna Pesatnya pertumbuhan teknologi masa kini telah membawa masyarakat ke dalam era digital. Hampir setiap aspek dalam kehidupan sehari-hari perlahan berubah menjadi serba digital, mulai dari internet banking, toko online sampai buku elektronik, dan lain-lain (Trisna:2014).

Membahas masalah era digital kita akan terbawa kepada suatu jaman yang serba canggih, manusia hanya berbekal sebuah computer yang terhubung secara online akan bisa mencari segala informasi yang diinginkannya, era digital ini jika di analisa dan dihubungkan dengan dunia perpustakaan pada akhirnya menjadi apa yang namanya digital library

Digital library merupakan suatu topik yang cukup menarik apabila kita kaji lebih jauh lagi, karena pada dasarnya digital libray memberikan suatu nilai yang luar biasa bagi perpustakaanperpustakaan dan pengembangannya (Putra, Andajani, \& Istiqomah, 2018). Kita banyak mengenal jenis-jenis perpustakaan. kesemuanya itu menginginkan untuk selalu berkembang baik dari Sumber Daya Manusia-nya juga Sumber Daya Alam-nya (teknologinya) namun kadangkala banyak kendala-kendala yang dihadapi perpustakaan dalam mengembangkan perpustakaanya, seperti dana, SDM, perangkat Teknologinya dan banyak lainnya. Disisi lain ada perpustakaan dengan kemampuan sumber dananya, SDM yang memiliki kredibilitas yang mumpuni tapi belum bisa mengembangkan perpustakaannya ke arah digitalisasi koleksinya (Digital Library)

Perpustakaan perguruan tinggi memiliki peluang yang lebih besar dalam mewujudkan perpustakaan berbasis digital karena perpustakaan perguruan tinggi selain di topang dengan dana yang cukup juga perguruan tinggi memiliki suatu koleksi local content berupa karya jurnal dan karya ilmiah produksi dari kalangan civitas akademika yang bisa dijadikan suatu materi dalam terbentuknya digitalisasi sumber-sumber tersebut, ini sebanding dengan pernyataan Saleh yang menyatakan bahwa perpustakaan digital ini diharapkan dapat menjadi solusi bagi perpustakaan konvensional yang biasanya mempunyai keterbatasan di dalam masalah koleksi. (Saleh:2010) 
Namun tidak semua perpustakaan perguruan tinggi bisa melakukan perubahan itu karena banyak kendala dan tatangan Perpustakaan perguruan tinggi sebagai salah satu penyedia informasi yang sangat penting kedudukannya dalam dunia informasi dan pendidikan harus dapat menjawab tantangan di era Teknologi informasi ini. Tantangan tersebut adalah bagaimana menyalurkan informasi dengan cepat, tepat, terkini, dan global.

Dalam hal menjawab tantangan ini maka banyak yang perlu dilakukan oleh pihak perpustakaan perguruan tinggi seperti melakukan bentuk perubahan dari katalog manual menuju otomasi perpustakaan yang kita kenal dengan nama. OPAC (Online Public Access Catalogue). Katalog ini hanya berupa daftar koleksi dan sumber perpustakaan tanpa terhubung dengan catatan peminjaman atau sumber eksternal.

Kemudian perpustakaan mampu melakukan suatu proses integrasi dari sistem manual menjadi otomasi perpustakaan, dan sistem informasi ini telah di lakukan sejak mulai tahun 1980an sehingga tahun 1990-an disini kita mulai menjadikan perpustakaan kita menuju "digital libray"

Dari tahapan-tahapan diatas merupakan proses dasar yang harus dilakukan oleh perpustakaan dalam menuju kepada digital library, namun masih banyak langkah-langkah yang harus di lakukan oleh perpustakaan perguruan tinggi dalam menuju institutional repository sebagai perwujudan digital library.

Perpustakaan Universitas Negeri Malang yang telah menerapkan institusional Repository sebagai sarana penyimpanan semua karya ilmiah baik dari mahasiswa, dosen dan seluruh civitas dengan nama "MULOK" tentunya berusaha menyajikan institutional repository sebagai perwujudan dan tolok ukur menuju digital library.

\section{METODE}

Metode penelitian yang digunakan adalah metode penelitian deskriptif analitis. yaitu ingin mengemukakan beberapa kemungkinan untuk memecahkan masalah yang aktual dengan jalan mengumpulkan data, menyusun, atau mengklasifikasikannya, menganalisa dan menginterprtesikannya. Hal ini juga dipertegas oleh Suharsimi yang mengemukakan bahwa "dalam penelitian deskriptif, peneliti berusaha menggambarkan keadaan sesuatu atau fenomena sebagaimana adanya" (Arikunto, 1992: 195)

Penelitian ini ingin menggambarkan Bagaimana membangun institusional repository Perpustakaan Universitas Negeri Malang (UM) Lokasi penelitian di Perpustakaan Universitas Negeri Malang

Populasi adalah keseluruhan subjek penelitian (Arikunto,1992:102) sedangkan menurut Suprianto menyatakan bahwa populasi adalah sekumpulan data yang lengkap dari elemen-elemen yang sejenis akan tetapi dapat dibedakan satu sama lain (Supranto, 1981:70) adapun populasi yang digunakan dalam penelitian ini adalah seluruh petugas tata usaha yang berjumlah 4 orang. Terdiri dari seorang Kasubag tata usaha, 2 staff Teknologi Informasi, 1 pustakawan

Teknik pengumpulan data dengan menggunakan teknik wawancara, dan observasi yang dilakukan peneliti agar mendapatkan data yang akurat. Sedangakan teknik analisa data dilakukan dengan metode diskriptif dengan menjabarkan temuan-temuan di lapangan.

\section{HASIL PENELITIAN DAN PEMBAHASAN}

\section{Hasil Penelitian}

Persoalan-persoalan dalam membangun institutional repository Perpustakaan Universitas Negeri Malang

Persoalan-persoalan yang dihadapi perpustakaan Universitas Negeri Malang dalam membangun Institusional Repository

\section{Hak Cipta ( Copy right)}

Undang-undang Nomor 19 Tahun 2002. Dalam undang-undang tersebut, pengertian hak cipta adalah "hak eksklusif bagi pencipta atau penerima hak untuk mengumumkan atau 
memperbanyak ciptaannya atau memberikan izin untuk itu dengan tidak mengurangi pembatasanpembatasan menurut peraturan perundang-undangan yang berlaku" (pasal 1 butir 1)

Berkaitan dengan hak cipta ini Perpustakaan Universitas Negeri Malang ini menjadikan suatu persoalan yang sangat rumit terhadap perpustakaan dalam menyelenggarakan Institusional Repository apabila tidak diikuti dengan perjanjian-perjanjian yang berlaku. Seperti misalnya terjadinya pro kontra ketika perpustakaan mengembangkan Institusional Repository-nya Utamanya terkait dengan dosen yang berkepentingan terhadap karya tulis mahasiswa yang dibimbingnya maka dari sini perpustakaan harus membuat suatu kebijakan tentang Institusional Repository adalah dengan Mengusulkan draft Surat Keputusan Rektor Tentang Wajib Serah Simpan Karya Ilmiah ke Perpustakaan.

Draft surat keputusan Rektor ini adalah suatu perjanjian antara mahasiswa dengan pihak perguruan tinggi, pernyataan terdapat hak bebas royalty Hak Bebas Royalti Non-Ekslusif (NoExclusive Royalty-Free Right) atas karya ilmiahnya Dengan Hak Bebas Royalti Non-Ekslusif ini Institut perpustakaan Universitas Negeri Malang berhak menyimpan, mengalih-media/formatkan, mengelola dalam bentuk pangkalan data (database), mendistribusikannya, dan menampilkan/mempublikasikan di Internet atau media lain untuk kepentingan akademis tanpa meminta ijin penulis/pencipta.

Kebiakan ini dibuat agar nantinya tidak ada gugatan secara hukum, karena sudah ada perjajian tertulis antara pihak-pihak terkait.

\section{Sumber Daya Manusia}

Dalam upaya agar perpustakaan berhasil dalam digital library adalah perpustakaan harus mampu menyediakan Sumber Daya Manusia yang profesional, artinya penanganan model perpustakaan digital ini harus di pegang oleh tenaga ahlinya di bidang ini.

Perpustakaan Universitas Negeri Malang dalam hal Sumber Daya Manusia masih memiliki kekurangan tenaga ini terlihat dari tenaga yang dimiliki, ada 1 orang yang menangani institusional repository ini, ini tidak sebanding dengan jumlah karya ilmiah yang dalam satu tahun bisa mencapai 12.000 judul karya yang harus diolah, diedit dan di upload dalam sistem institusional Repository yang di sebut "Mulok"

Untuk spesifikasi lulusan SDM dibagian IR ini sudah memiliki kualifikasi yaitu berasal dari lulusan komputer yang tentunya sudah paham terhadap ICT.

\section{Plagiarisme}

Dalam Kamus Besar Bahasa Indonesia plagiarisme adalah kata benda, yang artinya penjiplakan yang melanggar hak cipta". Tindakan melakukan plagiarisme disebut plagiat, yang berarti pengambilan karangan (pendapat dan sebagainya) orang lain dan menjadikannya seolaholah karangan (pendapat dan sebagainya) sendiri, misalnya menerbitkan karya tulis orang lain atas nama dirinya sendiri; jiplakan”. Orang yang melakukan tindakan plagiat disebut plagiator, yaitu "orang yg mengambil karangan (pendapat dan sebagainya) orang lain an disiarkan sebagai karangan (pendapat dan sebagainya) sendiri; penjiplak"

Dalam hal ini perpustakaan universitas Negeri Malang dalam mengembangkan Institusional Repository dalam hal Plagiarisme memang menjadi persoalan utama karena banyak kalangan mengkawatirkan dengan adanya Institusional Repository menyebabkan menjamurnya aksi-aksi plagiat yang dilakukan oleh orang-orang yang tidak memiliki kredibilitas dalam pembuatan suatu karya tulisan. Disamping itu perpustakaan Universitas Negeri Malang tidak memiliki alat pendeteksi plagiarisme, hal yang hanya dilakukan oleh pihak perpustakaan Universitas Negeri Malang yaitu Merubah format DOC ke PDF sebagai upaya untuk menghindarkan kegiatan plagiarism dan Pendidikan pemakai, upaya ini dilakukan agar pengguna mengerti ketentuan-ketantuan tentang kutipan-kutipan yang di perbolehkan. Dan kegiatan ini sebenarnya cukup bagus sebagai 
pengetahun terhadap pengguna-pengguna yang belum paham dan mengerti terhadap tindakan plagiat (kutipan).

\section{Tahapan-tahapan yang dilakukan oleh perpustakaan Universitas Negeri Malang Analisa Kebutuhan Pengguna}

Dalam proses tahapan membangun digital library dalam institusional Repository analisa kebutuhan pengguna sangatlah penting sekali karena dengan adanya analisa terhadap kebutuhan pengguna menjadikan program, sistem yang kita kelola menjadi berkembang dan sesuai dengan kebutuhan pengguna. Pendapat Tedd dan Andrew (2005) menyatakan idealnya sembelum membuat dan mendesain suatu sistem dalam digital library perlunya potensi analisa kebutuhan pengguna

Hal yang dilakukan perpustakaan universitas Negeri Malang yaitu melakukan survey kepada pengguna dengan menempatkan komputer survey yang ditempatkan di bagian layanan, survey ini juga bisa dilakukan di web perpustakaan, media sosial perpustakaan survey ini memiliki tujuan untuk mengetahui kebutuhan dan keinginan pengguna, serta menjadi solusi dari permasalahan yang dihadapi oleh pengguna, setelah melalukan survey maka perpustakaan Universitas Negeri Malang melakukan menganalisa kebutuhan pengguna, setelah proses analisa kebutuhan dirasa cukup, maka membuat daftar sederhana yang menggambarkan mengenai software yang akan dibangun termasuk batasan-batasannya.

\section{POB (Prosedure Operasional Baku)}

Perpustakaan Universitas Negeri Malang dalam hal ini telah membuat Prosedur Operasional Baku (POB) dengan tujuan membantu permasalahan rawan tentang HAKI (Hak Atas Kekayaan Intelektual)/Copyright. Sebagai contoh, pihak perpustakaan dapat menerapkan sistem perjanjian hak atas publikasi karya ilmiah sivitas institusi. Sehingga pihak penulis yang merasa kecewa tidak dapat menggugat pihak perpustakaan karena sudah ada standard dan aturan perjanjian yang berlaku. Dan juga perpustakaan universitas Negeri Malang membangun/membuat peraturan standar dan kebijakan dari pimpinan atau stakeholder institusi, misalnya: peraturan simpan karya ilmiah, Hal ini bertujuan untuk menghindari benturan kebijakan ketika proses penghimpunan koleksi dilakukan, dengan memiliki ijin dari pimpinan tinggi institusi maka para pustakawan sudah mempunyai kewenangan penuh untuk melakukan kegiatannya tanpa perlu ada kekuatiran munculnya hambatan secara personal atau organisasi.

Ini sejalan dengan apa yang disampaikan Hasan yaitu dalam membangun Institusional Repository yang juga perlu di lakukan oleh pihak pengelola/perpustakaan yaitu membuat Prosedure Operasional Baku (POB). POB ini berfungsi Sebagai pedoman dalam melaksanakan pekerjaan rutin. Sehingga pekerjaan akan berjalan dan berhasil apabila terdapat aturan yang ada.

\section{Sumber daya Manusia}

Sumber daya manusia ini dalam perpustakaan Universitas Negeri Malang adalah pengelola Repository karena Suatu unsur yang paling memiliki peranan adalah ada pengelola repository, pengelola repository adalah

1. Tenaga Teknologi Informasi

Dalam Tenaga Teknologi Informasi ini perpustakaan Universitas Negeri Malang melakukan penambahan 2 Tenaga Teknologi Informasi yang mempunyai tugas mengelola institusional Repository "Mulok, dengan tujuan petugas ini mempunyai prakarsa yang cukup penting. Seperti bagaimana membuat desain, system yang digunakan, sampai kepada hal-hal yang sangat urgent yaitu apabila system ini rusak, lambat ini adalah tugas dari petugas TI. Baik tidaknya format yang ditampilkan juga adalah peran dari seorang tenaga TI memback-up data sebagai langkah disaster planning.

2. Pustakawan 
Perpustakaan Universitas Negeri Malang selain menambah tenaga TI juga melakukan penambahan pustakawan jalur pegawai tidak tetap dengan memiliki kualifikasi mengerti tetang Teknologi Informasi (TI), tugasnya adalah mengelola data bibliografi karya ilmiah dengan Upload abstrak dan fullteks karya ilmiah. Kemudian pustakawan yang direkrut memahami terhadap kegiatan-kegiatan Preservasi koleksi digital. Keahlian pustakawan tersebut akan menjadi dasar perwujudan digital library yang dapat menjadi model dari suatu perpustakaan alternatif pada masa mendatang.

\section{Sarana dan prasarana (Hardware, Software) Hardware}

Upaya yang dilakukan oleh perpustakaan Universitas Negeri Malang yaitu menambah sarana dan prasarana hardware (Perangkat keras) keberadaan hardware ini merupakan salah satu faktor penting dari keberhasilan sebuah digital library, hardware yang dikembangkan oleh Perpustakaan Negeri malang yaitu diantaranya perangkat utama adalah Computer Personal (PC), Internet (Interconnected Network), dan world wide web (www)".

1. Komputer server disebut juga dengan komputer utama, server perpustakaan telah dilakukan penambahan kapasitas ini sebagai upaya menaggulangi begitu banyaknya data yang masuk kedalam sistem ini karna pada dasarnya di dalam komputer server ini yang nantinya sistem repository akan di install, untuk itu harus memiliki spesifikasi yang besar agar ketika nantinya sudah berjalan sistem ini tidak ada kata "Lambat dalam hal aksesnya" adapun pembahan di perpustakaan Universitas Negeri Malang sebagai berikut: Intel $($ Xeon $₫$ Processor E3-1220 v2 (8M Cache, $3.10 \mathrm{GHz}$ ) 32 Memory GB (4 DIMMs) System Management : HP iLO4 Management Engine, agentless Remote Management Validated System : Windows Server, Linux, VMware, Database My SQL.

2. Scanner, Scanner digunakan sebagai alih media teks ke format digital, Menurut Saleh (2010) menjelaskan "peralatan yang perlu dipersiapkan agar pembuatan dokumen digital lancar yaitu tersedianya perangkat keras seperti komputer dan scanner.

3. Audio/Video Converter digunakan untuk mengkonversi data audio dari bentuk kaset, audioCD, tape ke format multimedia masa kini seperti mp3,mp4, mpeg, dll.

4. MicroFilm Converter digunakan untuk menangkap gambar format microfilm untuk diubah ke bentuk gambar/slide

\section{Software}

Aplikasi Mulok yang dikembangkan sendiri, dengan alasan bisa menerapkan kebutuhan sesuai dengan kondisi pemakai dan sesuai dengan survey analisa kebutuhan pengguna. dalam pengembangan mulok maka perpustakaan merekrut tenaga-tenaga TI yang bisa melaksanakan pengembangan Insitusional Repository. Metadata yang digunakan oleh perpustakaan Negeri Malang Dalam menentukan aplikasi ini yang perlan sesuai du di perhatikan adalah metadata Doublin core yang memiliki 15 elemen, ini sesuai dengan pendapat dari Hasan (2010) Metadata merupakan struktur data yang berisi hal-hal yang menjelaskan tentang sebuah file, informasi atau data itu sendiri seperti: judul, pengarang, abstrak dan lainnya. Meta data yang banyak digunakan di Indonesia adalah Dublin core karena aplikasi yang sederhana dan nantinya bisa dikembangkan lebih lanjut, metadata Doublin core yang diterapkan oleh perpustakaan Universitas Negeri Malang memiliki 15 elemen yaitu :

1. Title: judul utama/tambahan dari karya ilmiah

2. Creator: pembuat karya ilmiah

3. Contributor: pihak yang terlibat dalam terciptanya hasil karya ilmiah.

4. Subject: pokok bahasan sumber informasi pustaka karya ilmiah.

5. Identifier: nomor identifikasi suatu karya ilmiah.

6. Description: keterangan tentang isi dari karya ilmiah.

7. Publisher: badan yang mempublikasikan karya ilmiah. 
8. Date: tanggal penciptaan karya ilmiah.

9. Type: jenis karya ilmiah.

10. Format: informasi bentuk fisik karya ilmiah.

11. Source: rujukan ke sumber asal suatu karya ilmiah.

12. Language: bahasa yang digunakan dalam karya ilmiah.

13. Relation: hubungan sumber informasi karya ilmiah.

14. Coverage: cakupan batasan sebaran informasi.

15. Right: informasi hak cipta.

Aplikasi dari mulok adalah Aplikasi PDF, Microsoft Word, Microsoft Excel terutama untuk dokumen teks. Sedangkan dokumen gambar (grafis) dalam format JPEG, GIF, dan, Ducument teks, Powerpoint, Paint, Adobe Photoshop.

\section{Konten Repository}

Konten repository yang di kembangkan oleh perpustakaan universitas Negeri Malang memiliki ruang lingkup karya-karya intelektual seluruh civitas akademika perguruan tinggi tersebut seperti

1. Tugas Akhir (Mahasiswa D1, D2, D3)

2. Skripsi (Mahasiswa S1)

3. Tesis (Mahasiswa S2)

4. Desertasi ( Mahasiswa S3)

5. karya-karya intelektual dari Civitas Akademika yang lain (Dosen, Karyawan, Guru Besar).

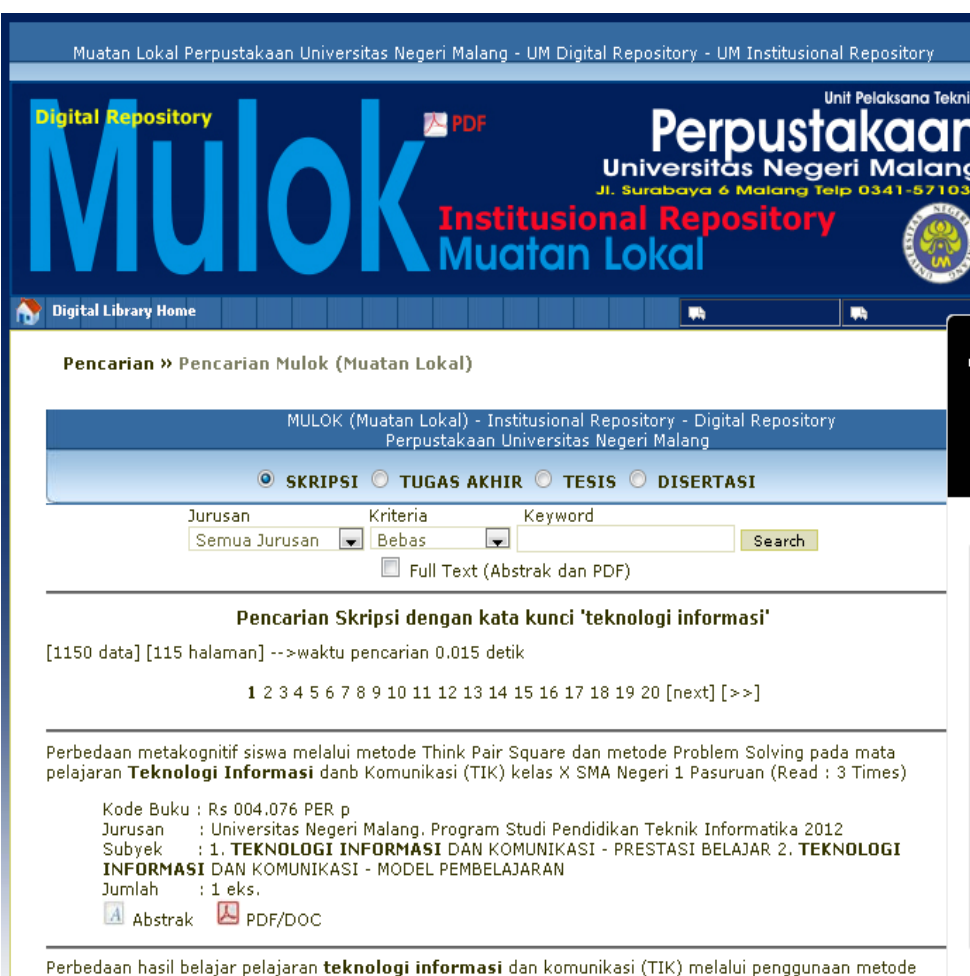

Perbedaan hasil belajar pelajaran teknologi informasi dan komunikasi (TIK) melalui penggunaan metode
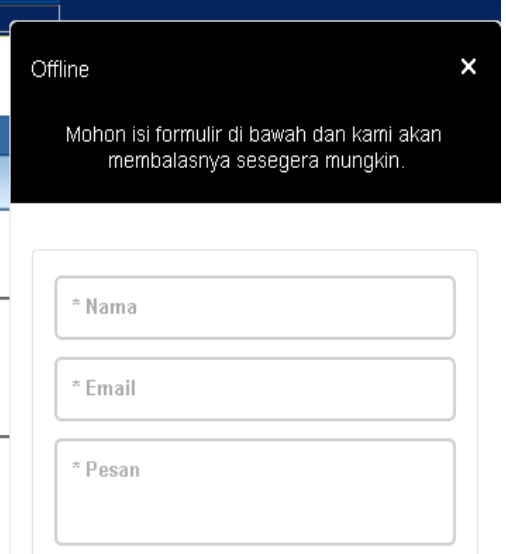

Kirim

We're 4 by tawk.to

Gambar: Konten Repository Perpustakaan Universitas Negeri Malang

\section{Back Up Data}

Proses untuk cadangan data (back up) yang dilakukan oleh perpustakaan Universitas Negeri Malang juga sudah dilakukan, ada dua proses back up data pertama dilakukan oleh Pusat 
Teknologi Informasi UM yang melakukan back up terhadap data mulok ini, dilakukan tiap hari. Kedua dilakukan back up oleh pihak TI perpustakaan dilakukan tiap tiga menit, tujuannya ingin menyelamatkan data mulok yang tersimpan, sehinggg perpustakaan sudah memiliki back up data tersebut. Ini sesuai dengan apa yang disampaikan Daryanto (2010) menyatakan "back up data bertujuan untuk menyelamatkan data yang penting, dengan memperbanyak data di komputer atau tempat lain sehingga apabila data tersebut hilang di komputer satu maka data tersebut ada di komputer atau tempat lainnya".. Pelaksanaan back up data, membuat pengguna lebih nyaman dalam mengamankan data pada komputer, apalagi data yang dimilki bersifat penting. Adanya back updata menjadikan data yang telah hilang, tetap dapat dimiliki, sehingga dapat melaksanakan manajemen koleksi. Manajamen koleksi diperlukan untuk proses perawatan koleksi, sehingga koleksi-koleksi yang tersimpan tetap mudah ditemukan dan diakses.

\section{KESIMPULAN}

Perkembangan Teknlogi Informasi membawa dampak yang luar biasa bagi kemajuan sebuah perpustakaan perguruan Tinggi, Perguruan tinggi yang memiliki sumber-sumber karya ilmiah yang dihasilkan dari civitas akademika tentunya sangat prospek dalam pengembangannya, agar seluruh karya muatan lokal di perpustakaan perguruan tinggi itu bisa di manage dengan baik maka perlu dikembangkan sebuah digital library yang di beri nama Institusional Repository yang tujuannya adalah sebagai preservasi karya-karya ilmiah seluruh civitas akademika, Institusional Repository memiliki tujuan adalah agar karya ilmiah itu tersimpan dengan baik, aman dan bisa dimanfaatkan untuk kepentingan ilmu pengetahuan. Banyak kendala dalam membangun institusional repository di Universitas Negeri Malang itu antara lain : 1. Masalah hak cipta, yang diselesaikan dengan cara dilakukan perjanjian tertulis agar nantinya tidak ada yang dirugikan satu dengan yang lain, 2. Masalah preservasi yang diambil tindakan dengan mengalih media dengan merubah format ke PDF sebagai upaya untuk melestarikan karya ilmiah tersebut, 3 Sumber Daya Manusia dengan memilih, menentukan standard tenaga yang betul-betul memiliki kemampuan dalam Teknologi Informasi, sumber Daya manusia yang ada di beri pelatihan ICT. 4. Plagiarisme Dengan melakukan beberapa tindakan termasuk peraturan-peraturan dalam men-copy serta diadakan bimbingan pemakai tentang baimana mengutip sebuah karya.

Tahapan-tahapan yang dilakukan oleh perpustakaan Universitas Negeri Malang yaitu. 1. Melakukan analisa kebutuhan pemakai sebagai upaya untuk menyikapi kebutuhan pengguna, sehingga program yang dihasilkan akan banyak dipergunakan oleh pemakai. 2. Pengelola Repository dengan merekrut tenaga ahli dan pustakawan yang menjalankan di beri pelatihan tentang ICT, 3 . Sarana dan Prasarana dengan menyiapkan Hardware (perangkat keras) dan Software (perangkat lunak) sebagai upaya agar aplikasi berjalan dengan baik, dan sukses. 4. Konten Repository yaitu menyipakan isi-isi dalam repository itu sendiri termasuk memasukkan (include) karya-karya dari pegawai, dosen dan guru besar). 5. Mem-Back-up data sebagai upaya tindakan pemeliharaan, pengamanan dari bahaya-bahaya seperti terjadinya data rusak, ataupaun bencana.

\section{DAFTAR PUSTAKA}

Arikunto, S. (2006). Prosedur Penelitian: Suatu Pendekatan Praktik, EdisiRevisi VI. Jakarta: PT Rineka Cipta.

Daryanto. (2010). Teknik Jaringan Komputer. Bandung: Alfabeta.

Hasan, N. (2010). Strategi Membangun dan Mengelola Institutional Repository Pada Lingkup Perguruan Tinggi. Surabaya, ITS.

Putra, D. A., Andajani, K., \& Istiqomah, Z. (2018). IMPLEMENTASI PRESERVASI DIGITAL KOLEKSI KARYA ILMIAH DI PERPUSTAKAAN MAULANA MALIK

INBRAHIM MALANG. BIBLIOTIKA: Jurnal Kajian Perpustakaan dan Informasi, 1(2), 2833.

Saleh, A. (2010). Membangun perpustakaan digital. Jakarta: Sagung seto. 
Supriyanto, W. \& Muhsin, A. (2008). Teknologi Informasi Perpustakaan: Strategi Perancangan Perpustakaan Digital. Yogyakarta: Kanisius.

Tedd, L. A. dan Andrew L. (2005). Digital Library: Principles and Practice in a Global Environment. Munchen: K.G. Saur.

Trisna, L. P. (2014). Penyelenggaraan Digital Library dalam Meningkatkan Layanan Perpustakaan bagi para Pemustakadi SMA Negeri 4. Malang. Malang. UM. 